\title{
STRATEGIC MARKETING PLANNING IN THE PRESENT-DAY ORGANIZATION
}

\author{
Dilyana Yaneva ${ }^{1}$
}

Received: 10.10.2020, Accepted: 29.10.2020

\begin{abstract}
Looking for business sustainability in conditions of uncertainty, organizations must pay serious attention to strategic marketing planning. Achieving the strategic goals of the company is closely related to the adaptation to the dynamic market conditions. This necessitates an in-depth study of the specifics of the process including analysis and evaluation of the marketing environment factors, mission formulation, general and marketing goals setting, segmentation, market selection, positioning, development, selection, implementation and control of marketing strategies.
\end{abstract}

Keywords: strategic planning, marketing planning, strategic marketing planning, organization, development

JEL Codes: M10, M30, M31

\section{Introduction}

An important prerequisite for market success in modern organizations is the integration of marketing activity into the business. Its main component is the planning process. It "takes place in every area of an organization, must be coordinated and must be compatible with the overall mission and with corporate objectives and strategy" (Wrenn \& Mansfield, 2014). In addition, company planning refers to the activities related to the definition of general objectives, analysis of trends in the development of the external environment and the definition of company resources and opportunities (Manov, 2001, p.23; Naydenov, 2020, p. 28).

It is clear that planning concerns the rationalization of the company's goals by exploiting company and market opportunities, anticipating, neutralizing or minimizing market risks and threats, overcoming company weaknesses. At the same time, the process contributes to the effective management of resources,

${ }^{1}$ South-West University "Neofit Rilski", Blagoevgrad, Faculty of Economics, Chief assist. prof., d_janeva@swu.bg; ORCID ID: https://orcid.org/0000-0003-3472-4595 
coordination between functional areas and facilitation control over the implementation of all company activities.

Marketing planning, on the other hand, includes a set of methods, techniques and tools for segmentation and selection of target markets, formation of the marketing mix, definition of marketing policy, implementation and control of marketing activities. An important point is the impact on consumers and competitors. The intercultural connections between them are also highly effective in this regard (Trojanowski, 2014, p. 68; Kiryakova-Dineva \& HadzhipetrovaLachova, 2017, p. 98).

According to some authors, marketing planning consists of two main phases - analytical and perspective (Mladenova, 2006, p. 32). Żyminkowska \& Żyminkowski (2014) divide them into analytical and behavioral (p.672). However, a third group of authors incorporates a third dimension into the process - organizational, related to corporate culture, organizational structure, management style, processes and information flows (Piercy, 2002, p. 586; Harris, 1996, p.40; Gilligan \& Wilson, 2012, p.58).We emphasize the importance of this stage, because in our opinion it reveals the value system and the views of senior management and employees, which inevitably has a significant impact on the competitiveness and development of the company.

These aspects are caused by the emergence of a new modification of internal planning and management in recent years - strategic planning (Veselinova, 2014, p.5). Its main objectives are to seek answers to the following questions:

- What is the desired state to which the organization aspires?

- What are the main drivers of change?

-What are the main ways - activities to reach the desired state?

- Do the achieved results correspond to the set goals?

It can be summarized that strategic planning is about outlining the direction to achieve the goals by exploring alternatives, measuring results and creating values.

The purpose of the article is to present the characteristics of strategic marketing planning and its importance for the prosperity of the modern organization. 


\section{Definition and role of strategic marketing planning}

Strategic planning of marketing actions determines the need to take specific measures to identify the strengths of the company and opportunities, outlining key competencies and gaining a competitive advantage of the organization. It should not be neglected the threats from the external environment, which the company must constantly monitor, analyze and evaluate by adapting its activities to them.

A key role in the process is played by the formulation, evaluation and implementation of a marketing strategy, plan and programs. In this regard, Gilligan and Wilson (2012) support the thesis that strategic marketing planning covers a period of three to five-year period and it is "concerned with the development of strategies that are based on the planning team's assessment of the market and perceptions of managerial expectations and organizational capability (p.44). According to Mladenova (2006), strategic marketing planning covers all levels of management and the main unit is the business level. Regarding the financial aspect, the author considers a number of financial indicators related to the expected financial results, the degree of risk, the necessary financial resources and the priorities for their distribution (p.22).

The literature review shows the diversity of the author's opinions regarding the technology of strategic marketing planning (Gilligan \& Wilson, 2012, p.55; Drummond, Ensor \& Ashford, 2007, p. 242-244; Mladenova, 1998, p. 21). According to a number of authors, the process includes analysis of the external and internal company environment, development of forecasts, definition of the mission and goals, choice of strategy, development of a strategic plan, implementation of plans, control (Madgerova, et al., 2012, p.110). Blagoev (1998) discusses the process in more detail, including the stages of presenting the results of marketing research, segmentation, selection of target market and positioning, strategic marketing analysis, SWOT analysis, marketing programs and budget of marketing activities (p.245).

Figure 1 illustrates the process algorithm which, in our opinion, includes the following seven main steps.

\section{Stages and characteristics of strategic marketing planning}

Mission is the general goal, which reveals the general strategic focus of the company. It is related to its history, activity, development guidelines, markets, customers, products. Its correct formulation will help not only to differentiate from competitors and orient to consumers, but also to identify employees with the company. Therefore, an important role here is the corporate culture, values, 
organizational structure, management style, etc. In this regard, F. Kotler argues that the business mission is influenced by five main factors: company history, market environment, available resources, competitive advantages of the company and management team preferences (Kotler, 1997, p. 69)

Figure № 1. Algorithm of the strategic marketing planning process

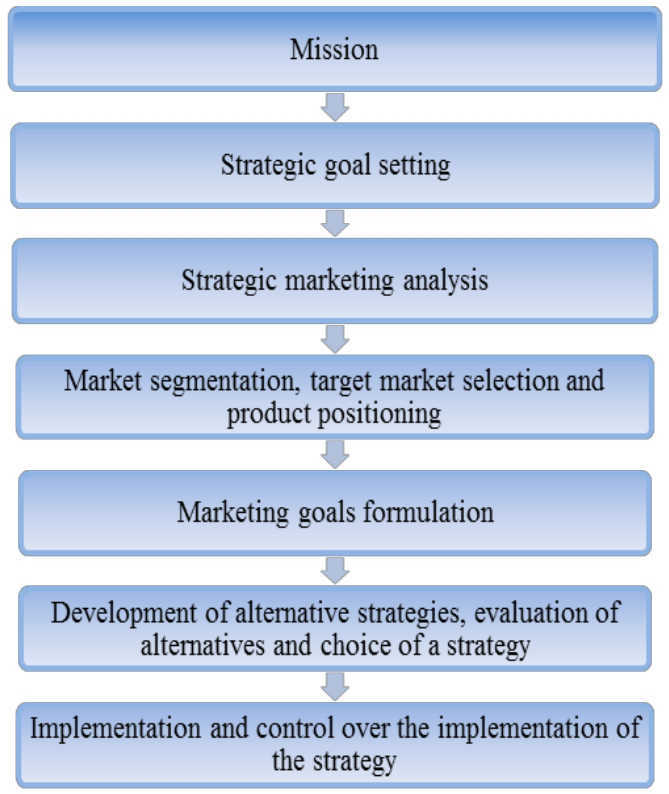

Source: composed by the author

Present-day organizations must pay due attention to scientific, technological progress and innovations but they must also not forget the corporate social responsibility and implement it in the corporate mission. In this way, they will give meaning and value to consumers by fully meeting their needs.

There is a relationship between mission, goals and objectives (Rouillard, 2003 , p.14). Strategic goal setting requires a clear definition of the direction of long-term development of the company by showing what should be the efforts of management. The process is related to the search for the desired company status based on analysis and forecasts of the environment, assessment of resources, organization activities, management functions, social corporate responsibility, collective goal setting, communication, hierarchical subordination, etc. The process technology includes defining and analyzing the factors and trends in the 
external and internal company environment, determination of general goal and decomposed company goals and building a "tree of objectives".

For effective strategic marketing planning is necessary for businesses to know the characteristics and factors of external and internal marketing environment. Strategic marketing analysis occupies a key place here. It is a starting point for developing reliable marketing strategies and making the right strategic decisions. Its three main areas are related to the knowledge, definition, analysis and evaluation of:

- economic, demographic, social, technological, natural, environmental, political and other conditions;

- trends in the tastes and needs of consumers; competitors' goals, policies and strategies; relationships with suppliers, distributors, banking institutions, etc.;

- internal functional areas (production, finance, human resources, etc.) and their connection with the marketing process.

The literature review shows that the main methods of strategic planning are divided into the following areas:

- calculation-analytical (balance, normative, technical-economic);

- graph-analytical (extrapolation, network, regression-econometric, correlation);

- economic-mathematical (linear, nonlinear and dynamic programming, game theory, queuing);

- heuristic (expert assessments, scenario method) (Brankova, 2009, p.37).

Among them, SWOT analysis, the model of Michael Porter and portfolio models are the most widely used.

Priority place in the process of strategic marketing planning is given to segmentation, selection of target market and product positioning in the market. Customer focused companies master the flexibility and adaptability of their marketing activities and the decisions they have to make, thus forecasting their reaction and striving to better meet their needs. It is not only necessary to segment the market well and choose an effective market segment, but also to study consumer needs, to track behavior and seek their opinion, to create long-term and sustainable relationships and connections with them. That is why feedback plays an important role in this process.

Our opinion is that market segmentation goes through the following stages:

- choice of market coverage approaches;

- development of segmentation criteria;

- determination of a leading criterion; 
- developing alternative market segments;

- analysis and evaluation of potential segments;

- segment selection.

Another important aspect of the market development process is product positioning. The construction of a positive desired image in the minds of consumers is inevitably associated with the creation of uniqueness and sustainable competitive advantages of the product, brand and company. The main specific features of the positioning can be highlighted social status, importance, qualities, strengths and weaknesses, characteristics, price and value for the consumer (Harisson, 1987, p.7). Building such a concept is unthinkable without knowing and managing the factors that affect the process, positioning parameters, knowledge of competitors and their strategies, schemes and positioning strategies.

The marketing goals outline the ways to reach the defined directions for development, i.e. marketing activities to specify the expected results of marketing efforts. This stage serves as a basis for developing a marketing strategy. The main marketing decisions that need to be made concern the marketing tools and are related to market and business trends, factors of the marketing environment, current and future demand, sales volume, available resources, consumer needs, preferences and their dynamics. This type of goals must meet certain requirements such as accuracy, clarity, specificity, consistency, achievability, quantitative measurability, time measurability, interconnectedness with the general company goals, resource security, etc.

After completing the preparation of the entire process of strategic marketing planning, it can be proceed to the development of strategic alternatives, evaluation of alternatives and choice of strategy. Proposal formulation is based on marketing analyzes, formulated corporate and marketing goals, available resources, budget, expected results, etc. Using a rich set of models, methods, approaches, financial and non-financial indicators, the strategic effectiveness of the options is assessed. We believe that the methods Balanced Scorecard, Skandia Navigator and Performance Prism are extremely suitable. At the same time, tactical marketing tools such as a marketing plan and programs should be developed, on the basis of which the activities, responsibilities, resources, funds, etc. will be distributed.

The implementation and control of the chosen strategy requires the creation of certain conditions for its organizational provision, understanding and perception of human resources in the organization, making adjustments if necessary. An important condition is to constantly monitor the state and dynamics 
of the environment and the results achieved by adopting appropriate behavior and adequate monitoring measures.

Ferrell and Hartline (2007) have made a significant contribution to the research. They adopt four techniques for implementing the marketing strategy:

- "by command" - by imposing a strategy by senior management;

- "through change" - the company changes its activities so as to adapt to the chosen strategy;

- "by consensus" - joint development of the strategy and determination of the ways for its implementation by the managers of all functional areas of the company;

- "organizational culture" - aims to be perceived by all employees (p.325 $-326)$.

Supporting the opinion of Jaworski, we believe that the control process is divided into formal and informal. The first type consists of control activities initiated by the management process and it is incoming, processing and outgoing. At the same time, the informal concerns control activities initiated by the employees, including: self-control of the employees, social control and cultural control (cited by Ferrell \& Hartline, 2007, p. 330).

\section{Conclusions}

Strategic marketing planning as a philosophy of thinking and a basic management function outlines the activities for achieving the general and marketing goals of the company in a long term. The process analyzes the situation, anticipates the changes, coordinates the activities and functions and formulates the adaptation or change. In order to improve the company's competitiveness and development opportunities, organizations need to study and know this process in depth. 


\section{REFERENCES}

Blagoev, V. (1998). Marketing. Sofia: VEKKO.

Brankova, B. (2009). Methods and models for strategic decisions in the management of production enterprises, Yearbook of the University of Mining and Geology "St. Ivan Rilski", 52, IV: Humanities and Economics, Sofia: University of Mining and Geology Publishing House, 37-41.

Drummond, G., Ensor, J. \& Ashford, R. (2007). Strategic Marketing: Planning and Control. Routledge.

Ferrell, O. \& Hartline, M. (2007). Marketing Strategy. Cengage Learning.

Gilligan, C. \& Wilson, R. (2012). Strategic Marketing Planning. Burlington: Routledge.

Harris, L. (1996). The application of Piercy and Morgan`s dimensions of marketing planning, Management Decision, 34 (3), 35-40.

Harisson, T. (1987). Handbook of Advertising Techniques. London: Kogan Page.

Kiryakova-Dineva, T. \& Hadzhipetrova-Lachova, M. (2017). Intercultural management - aspects and perspectives for the business practice of the organization, Entrepreneurship Journal, V (1), 97-105.

Kotler, P. (1997). Marketing management: analysis, planning, implementation and control. Prentice Hall, Upper Saddle River.

Madgerova, R. et al. (2012). Organization and management of small business. Blagoevgrad: Langov.

Manov, V. (2001). Forecasting and planning the development and functioning of economic systems. Sofia: University for national and world economy Publishing House.

Mladenova, G. (2006). Marketing planning. Sofia: University for national and world economy Publishing House.

Mladenova, G. (1998). Strategic Marketing Planning. Sofia: University for national and world economy Publishing House.

Naydenov, N. (2020). Forecasting and planning. Sofia: University for national and world economy Publishing House.

Piercy, N. (2002). Market-Led Strategic Change. Transforming the Process of Going to Market. Butterworh-Heinemann.

Rouillard, L. (2003). Goals and Goal Setting: Achieving Measured Objectives. USA: Cengage Learning. 
Trojanowski, T. (2014). Culture of Marketing Actions of a Company in the Area of Sustainable Marketing Mix, Journal of Intercultural Management, 6(42), 67-74.

Veselinova, N. (2014). Marketing planning process in conditions of uncertainty of the environment, E-Journal VFU, 7, Varna: Varna Free University Publishing House, 1-14.

Wrenn, B. \& Mansfield, Ph. (2014). Marketing Planning Guide. Routledge.

Żyminkowska, K. \& Żyminkowski, T. (2014). Analytical and behavioural elements of marketing planning model - empirical evidence from Polish firms, International journal of economic practices and theories, 4 (5), 668 676. 